\title{
Consciência ambiental relacionada aos resíduos sólidos urbanos em Faro- Portugal
}

\author{
Bruno Acosta Flores, Pedro Daniel da Cunha Kemerich, Joseane Kolzer Schroeder, Maurício Piovesan, \\ Willian Fernando de Borba
}

Laboratório de Planejamento e Monitoramento Ambiental - LPMA/UFSM,

Curso de Engenharia Ambiental da Universidade Federal de Santa Maria - UFSM/CESNORS

\begin{abstract}
Resumo
Com o aumento da população, a geração de resíduos sólidos urbanos (RSU) aumentou gradativamente, desta forma surge tecnologias adequadas para a disposição adequada desses resíduos, sendo uma delas os aterros sanitários. O presente estudo aborda a situação do município português, Faro (região sul do país) referente aos RSU, e a conscientização da população referente aos mesmos. Trata-se de um estudo exploratório, com abordagem qualitativa e quantitativa de investigação, cujos entrevistados constituem um universo de 250 pessoas de diferentes classes sociais, idades e escolaridades. Para a realização deste trabalho, elaborou-se um questionário contendo 18 perguntas, sendo estas divididas em nove questões objetivas e outras nove questões subjetivas, com o intuito de caracterizar os hábitos e a consciência ambiental da população portuguesa perante o descarte incorreto e os impactos relacionados aos Resíduos Sólidos Urbanos. Após a aplicação do questionário, as principais respostas obtidas foram analisadas e representadas graficamente através do software Microsoft Excel 2010 para melhor visualização e discussão. Faro possui o sistema de coleta seletiva, o que auxilia a conscientização a comunidade. Percebe-se desta forma que o grande público de 250 pessoas entrevistadas adere às questões sustentáveis, porém, ainda não há toda comoção necessária em prol do meio ambiente para que consigamos completar um ciclo de uso e reuso até o descarte final.
\end{abstract}

Palavras-Chave - Residuos solidos urbanas, disposição adequada, consciência ambiental.

\begin{abstract}
With the increase of the population, the generation of solid waste municipal (SWM) has increased gradually in this way appears appropriate technologies for proper disposal of this waste, one of the landfills. This study addresses the situation of the Portuguese municipality, Faro (Southern region) for MSW, and public awareness regarding the same. This is an exploratory study with a qualitative and quantitative research, the respondents constitute a universe of 250 people of different social classes, ages and schooling. For this work, we elaborated a questionnaire containing 18 questions, which are divided into nine objective questions and nine other subjective issues, in order to characterize the habits and environmental awareness of its population to the incorrect disposal and impacts related to Municipal Solid Waste. After the questionnaire, the main responses were analyzed and graphed using the software Microsoft Excel 2010 for better viewing and discussion. Faro has a selective collection system, which helps the community awareness. It can be seen therefore that the large audience of 250 people interviewed adheres to sustainable issues, however, there is no commotion all needed in favor of the environment so that we can complete a cycle of use and reuse to the final disposal.
\end{abstract}

keywords - solid waste municipal, proper disposal, environmental awareness. 


\section{INTRODUÇ̃̃O}

Os hábitos de consumo proporcionados pelo desenvolvimento urbano traduzem-se hoje por uma excessiva produção de resíduos que, pela sua qualidade e quantidade, constitui a causa de uma das mais importantes disfunções ambientais (TROTTA, 2011). O atual molde social se baseia na exploração de recursos naturais para a produção de bens a serem consumidos e descartados em ritmo acelerado, geram passivos ambientais que podem atingir grandes proporções e colocar em risco liberdades individuais como a saúde do meio natural (POLZIN, 2004).

Segundo a norma brasileira NBR 10004, de 2004 - Resíduos sólidos são:

Aqueles resíduos nos estados sólido e semi-sólido, que resultam de atividades da comunidade de origem industrial, doméstica, hospitalar, comercial, agrícola, de serviços e de varrição. Ficam incluídos nesta definição os lodos provenientes de sistemas de tratamento de água, aqueles gerados em equipamentos e instalações de controle de poluição, bem como determinados líquidos cujas particularidades tornem inviável o seu lançamento na rede pública de esgotos ou corpos de água, ou exijam para isso soluções técnicas e economicamente inviáveis em face a melhor tecnologia disponível".

Os Resíduos Sólidos Urbanos (RSU), antes entendidos como meros subprodutos do sistema produtivo, atualmente passam a ser encarados como responsáveis por graves problemas de degradação ambiental, cujos danos causados tornaram-se mais evidentes com o passar dos anos (OLIVEIRA, 2011).

Em Portugal o volume crescente de resíduos sólidos urbanos transformou-se num problema para os municípios, principalmente no que tange à escassez de espaço para dispor os mesmo. A solução mais utilizada até a poucos anos para este problema era a deposição no solo em lixões, com os inconvenientes daí decorrentes em termos ambientais, de saúde pública e até econômicos. Nos últimos anos começaram a construir diversos aterros sanitários, com exploração controlada, para a colocação dos RSU como solução final (FERNANDES, 1999).

A gestão de Resíduos sólidos urbanos em Portugal iniciou-se tardiamente, se considerarmos que os primeiros passos foram dados em 1985 e o sistema iniciou-se passados onze anos, em 1996.
O sistema teve sua evolução após a publicação do Plano Estratégico de Gestão dos Resíduos Sólidos Urbanos (PERSU), onde ficou instituído o princípio dos três R's, as atribuições de responsabilidades, a estrutura de gestão dos Resíduos sólidos Urbanos (RSU), as metas e os objetivos (POLZIN, 2004).

A política de resíduos portuguesa tem por base o princípio dos três R's, reafirmando a responsabilidade do produtor pelos resíduos que produz (ISEL, 2001).

- Reduzir a produção e/ou nocividade dos resíduos;

- Reutilizar: dar novo uso aos resíduos; e

- Reciclar: transformar os resíduos em matérias- primas industriais.

Através do Plano Estratégico Setorial de Gestão dos Resíduos Sólidos Urbanos, foi elaborado um programa de coleta seletiva dos resíduos, de maneira facilitar a reciclagem. Posteriormente foram criados pontos de coletas para cada tipo de material, divididos em vidro (verde), papel/ cartão(azul), metais e plástico(amarelo).

No município de Faro, a separação e a coleta dos resíduos funcionam de forma organizada e satisfatória. Os resíduos gerados são colocados em pequenos containeres, separados por cores e distribuídos junto às habitações, em pontos de coleta, conhecidos como Ecopontos (figura 1). A coleta é feita de forma organizada, evitando a mistura dos resíduos, tendo dias específicos para coleta de cada material, sendo coletado por veículos próprios, chegando em dias distintos cada material até o aterro, desta forma facilitando o processo no aterro sanitário, que é abastecido por resíduos gerados em toda região do Alguarve, que produz o mesmo sistema de coleta seletiva.

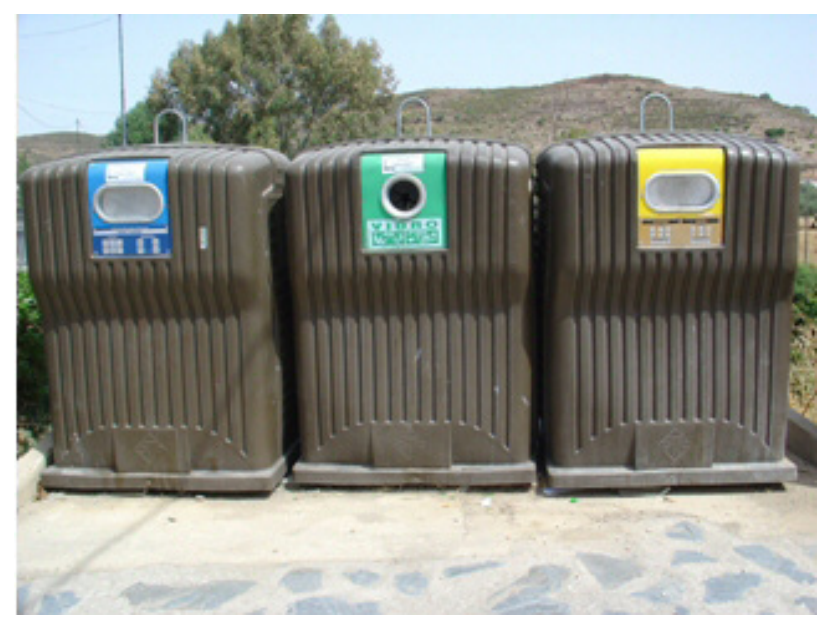

Figura 1 - Ecopontos Superficiais

Fonte: alcoutin.com.br 


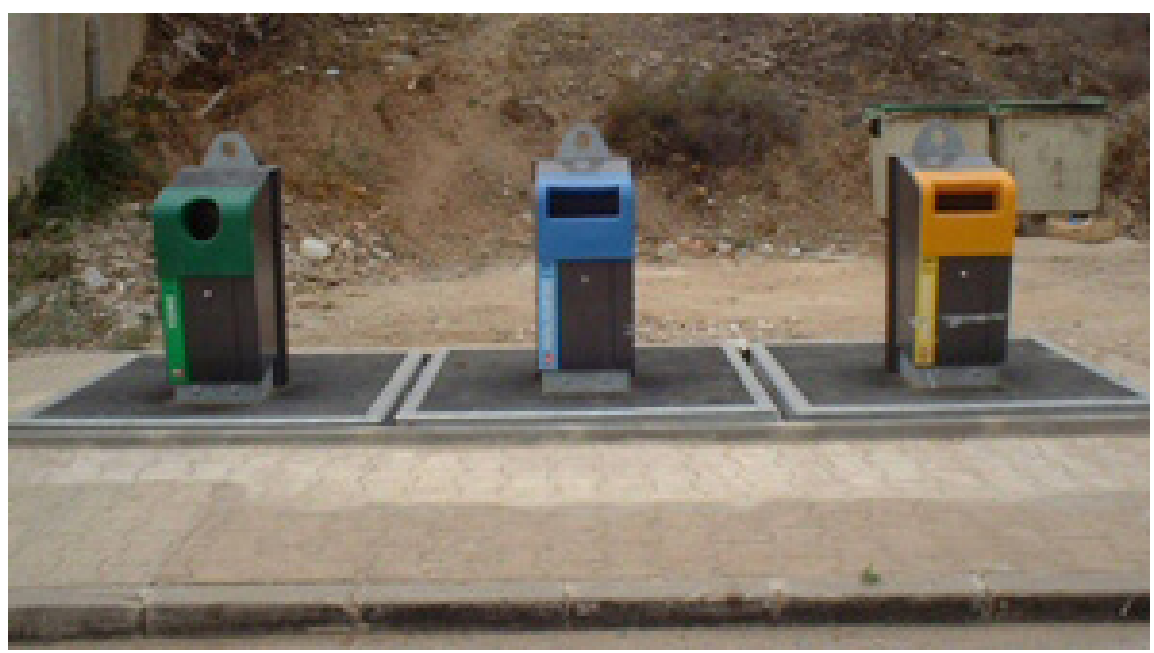

Figura 2- Ecopontos Subterrâneos

Fonte: alcoutin.com.br

Além dos ecopontos superficiais, em Faro e toda região do Algarve, dispõem de equipamentos subterrâneos (figura 2), com diferentes capacidades de contemporização, para colocação dos resíduos indiferenciados nas proximidades das suas habitações, os quais são recolhidos da mesma forma que os ecopontos superficiais.

Após a implementação da coleta seletiva em toda a região do Algarve, é perceptível o aumento da coleta dos materiais passíveis de serem reciclados, como mostra a figura 3.

A produção de resíduos por habitante varia bastante no país, dependendo do nível de vida da população, ou seja, do grau de desenvolvimento do país. Segundo Polzin (2004), a produção média por habitante de RSU's, em Portugal, tem aumentado.
Em 1995, o valor era de 0,92 Kg/dia e, em 200, o valor subiu para $1,29 \mathrm{Kg} / \mathrm{hab} / \mathrm{dia}$. Associa-se este desenvolvimento a maior variedade de produtos colocados à disposição do consumor. Os resíduos sólidos são muito heterogêneos. Segundo o PERSU os RSU apresentam a seguinte constituição: materiais fermentáveis $(36,0 \%)$, papel e cartão $(22,3 \%)$, finos $(12,9 \%)$, plástico $(12,7 \%)$, vidro $(4,9 \%)$, têxteis $(3,7 \%)$, metais $(2,9 \%)$ e outros $(4,9 \%)$.

$\mathrm{O}$ maior problema referente à coleta desses resíduos é a falta de conscientização da população, que muitas vezes não realizam o correto descarte dos mesmos. Sendo assim, a melhor maneira de combater a problemática do descarte incorreto dos RSU's é partir para o processo de Educação Ambiental.

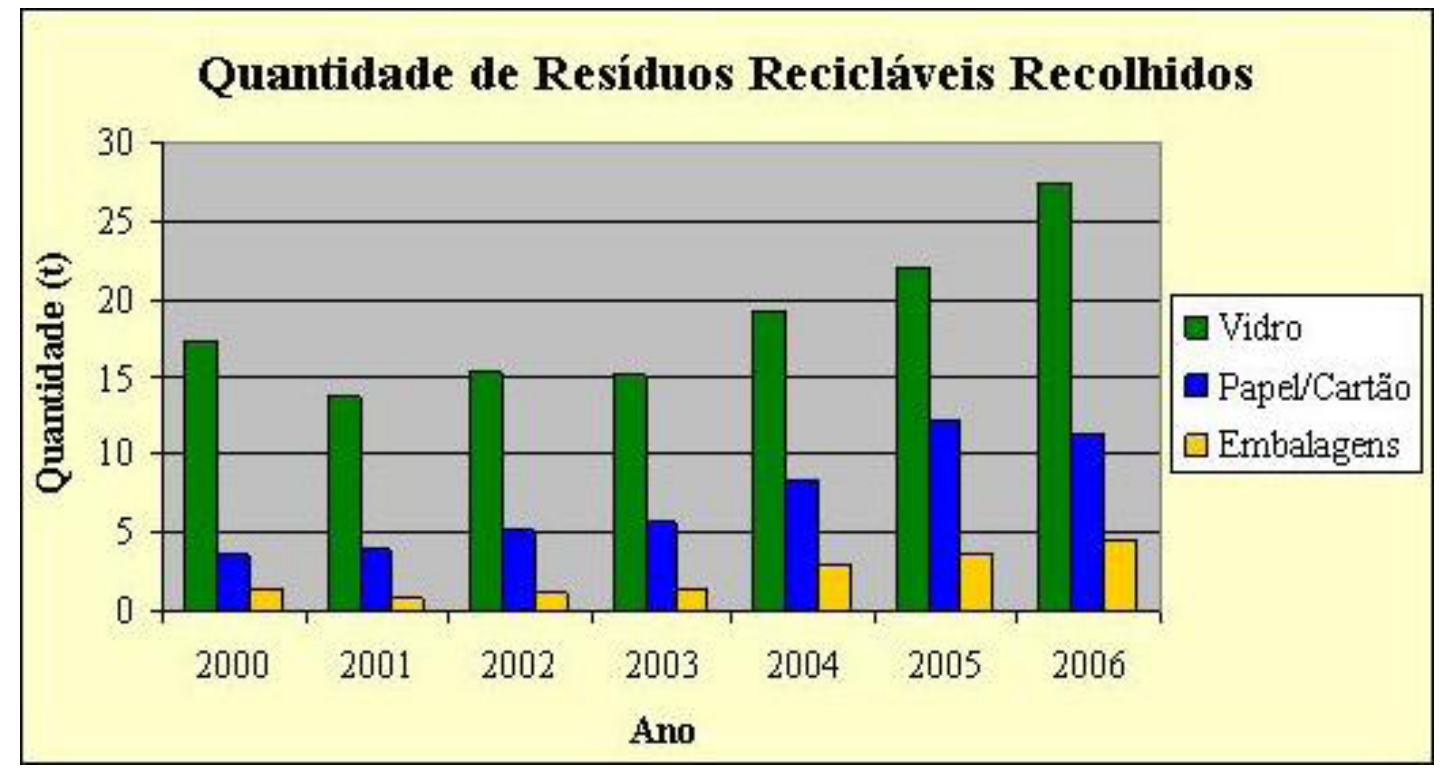

Figura 3- Quantidade de Resíduos recicláveis recolhidos

Fonte: alcoutin.com.br 
A educação ambiental constitui um processo informativo e formativo dos indivíduos, desenvolvendo habilidades e modificando atitudes em relação ao meio, tornando a comunidade educativa consciente de sua realidade global. Tem como finalidade despertar a preocupação individual e coletiva para a questão ambiental com uma linguagem de fácil entendimento que contribui para que o indivíduo e a coletividade construam valores sociais, atitudes e competências voltadas para a conservação do meio ambiente (DIAS, 1992). A educação e conscientização ambiental são fatores determinantes em todo processo de gerenciamento dos resíduos, pois a responsabilidade é de toda a sociedade não podendo ser excluída nenhuma parte dela, nem mesmo as pessoas com dificuldades de acesso os meios de comunicação.

\section{OBJETIVOS}

Os principais objetivos do trabalho são:

- Verificar os hábitos da população portuguesa do que se refere à consciência ao descarte e gerencialmente de resíduos sólidos urbanos;

- Verificar a diferença cultural entre Brasil e Portugal, em relação ao gerenciamento de resíduos;

- Observar métodos de coleta dos RSU em Portugal, para servir de sugestão para aplicação no Brasil.

\section{METODOLOGIA}

O presente estudo foi desenvolvido no município de Faro que é uma cidade portuguesa com 43528 habitantes, capital do Distrito de Faro, da região, sub-região e ainda da antiga província do Algarve que ocupa uma área de $5,412 \mathrm{~km}^{2} \mathrm{e}$ onde residem 451005 habitantes (INE, 2011). É sede de um município com $201,59 \mathrm{~km}^{2}$ de área e 64560 habitantes (2012), subdividido em seis freguesias(é o nome que tem, em Portugal e no antigo Império Português, a menor divisão administrativa, correspondente à paróquia civil de outros países). O município é limitado a norte e oeste pelo município de São Brás de Alportel, a leste por Olhão, a oeste por Loulé e a sul tem costa no Oceano Atlântico. Possui o Aeroporto de Faro, sendo ele o responsável pela segunda maior entrada externa do país, sendo a maior entrada, na capital Lisboa.
Trata-se de um estudo exploratório, com abordagem qualitativa e quantitativa de investigação, cujos entrevistados constituem um universo de 250 pessoas de diferentes classes sociais, idades e escolaridades. Para a realização deste trabalho, elaborou-se um questionário contendo 18 perguntas, sendo estas divididas em nove questões objetivas e outras nove questões subjetivas, com o intuito de caracterizar os hábitos e a consciência ambiental da população portuguesa perante o descarte incorreto e os impactos relacionados aos Resíduos Sólidos Urbanos.

Após a aplicação do questionário, as principais respostas obtidas foram analisadas e representadas graficamente através do software Microsoft Excel 2010 para melhor visualização e discussão.

\section{RESULTADOS E DISCUSSÃO}

Os resultados e discussões são baseados no questionário aplicado para 250 moradores de Faro, onde é possível perceber as diferenças de opinião e cultural entre cada entrevistado em uma mesma cidade. Esta situação pode ser acompanha a seguir:

\section{I Caracterização do público estudado}

Primeiramente, é importante caracterizar o universo de pessoas que responderam ao questionário, desta forma, foram introduzidas questões referentes à escolaridade do entrevistado, sendo importante para contrastar com o conhecimento adquirido até então. Os dados podem ser vistos na figura 4.

Com base no gráfico, pode se perceber que a grande maioria do público entrevistado possui um bom grau de instrução, pois estão em fase de formação, estando com o curso superior incompleto.

A valorização da natureza e a preocupação com o futuro do planeta tem se destacado entre grupos jovens, percebe-se isso devido a forte presença de adolescentes entre os voluntários e ativistas de grandes ONGs ambientais como o Greenpeace, Amigos da Terra, World Wildlife Foundation (WWF) entre outras (CARVALHO, 2004).

Em relação à renda familiar, a maior parte das pessoas, cerca de $72 \%$ (180/250) não souberam ou não quiseram opinar. Isto se deve principalmente ao fato de que o universo amostral estudado é bastante dinâmico e possui jovens de diferentes países fazendo intercâmbio na Universidade do Algarve. O restante das respostas obtidas se dividiu de acordo com a figura 5 . 


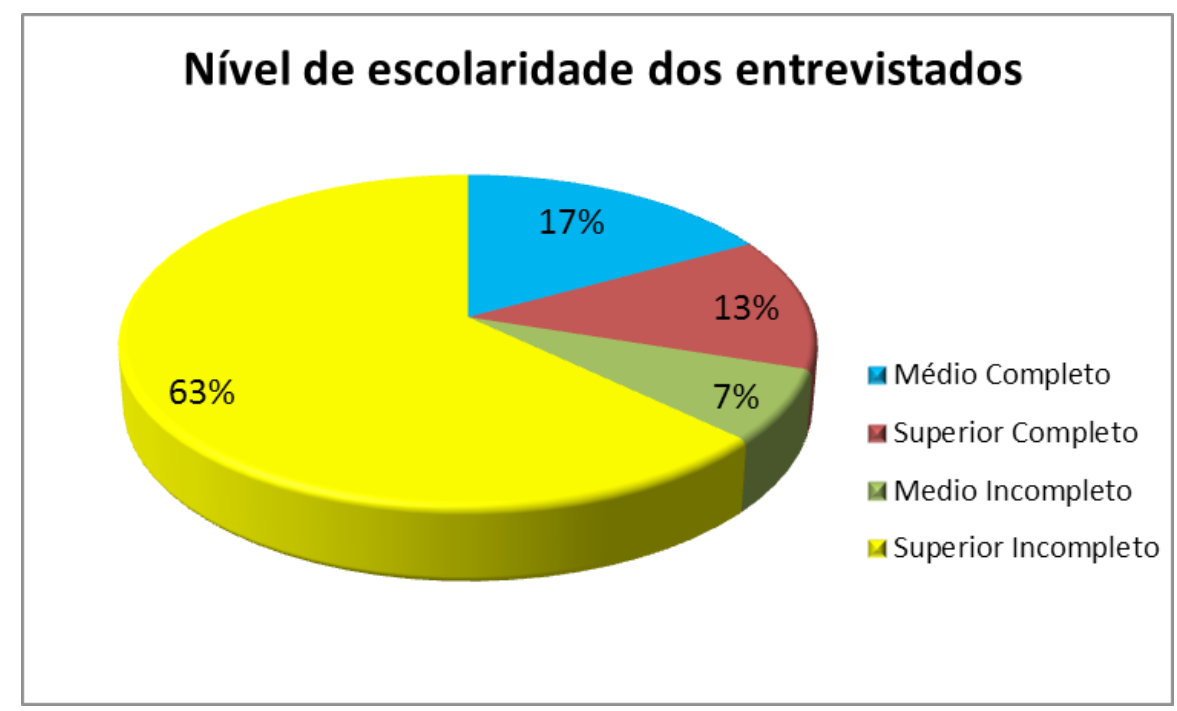

Figura 4. Escolaridade dos entrevistados

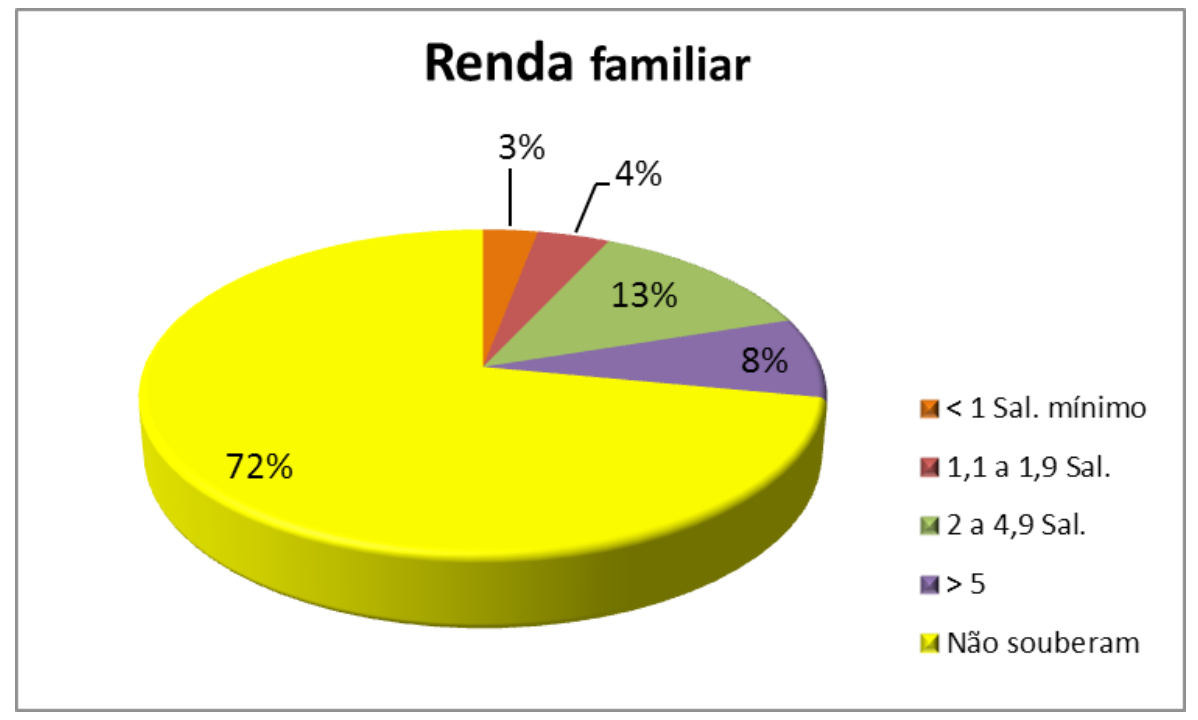

Figura 5. Renda familiar dos entrevistados.

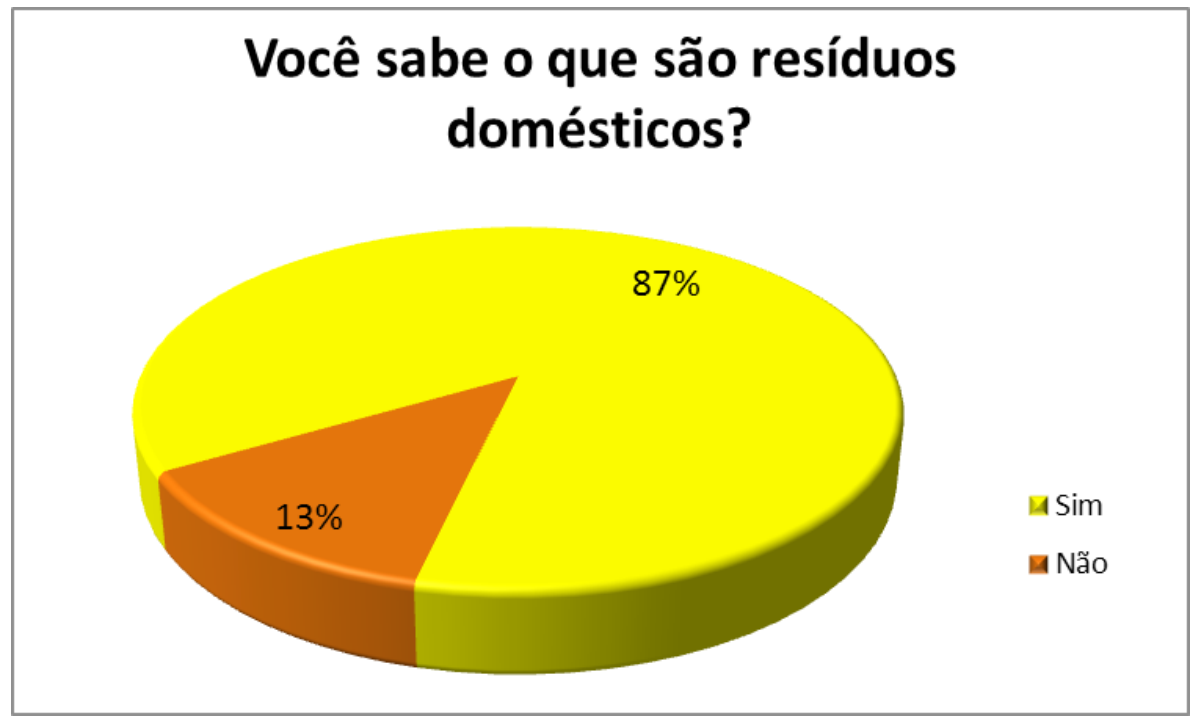

Figura 6. Conhecimento acerca dos resíduos domésticos. 


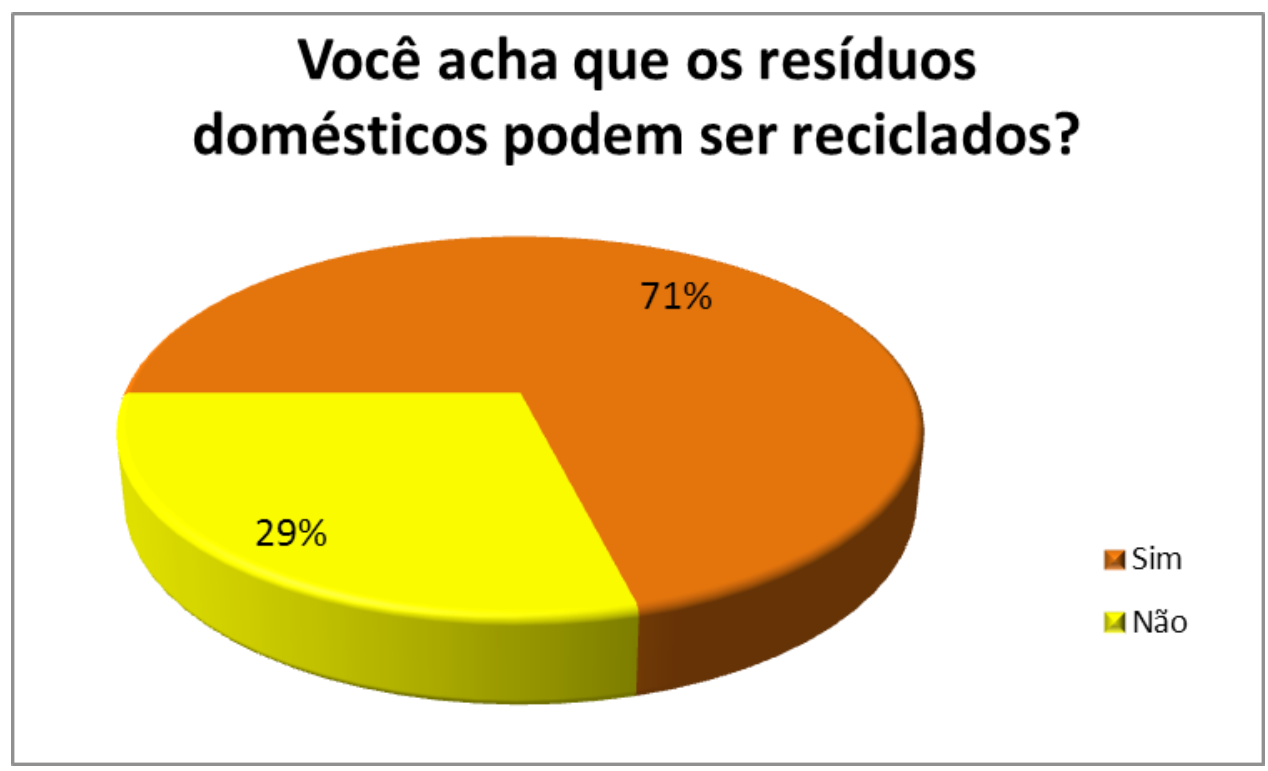

Figura 7. Reciclagem de resíduos domésticos.

\section{sustentáveis}

Preocupação ambiental e demais hábitos

Com o intuito de observar o conhecimento dos entrevistados sobre questões pertinentes ao meio ambiente, a primeira pergunta inferiu que a grande maioria, cerca de $87 \%(217 / 250)$ possui o conhecimento sobre o que são resíduos domésticos. Entre as respostas houve maior frequência para restos de comida, embalagens, latas e garrafas pet.

As questões dois, três, quatro e cinco referiam-se principalmente aos hábitos em relação à separação e descarte de resíduos. Quando perguntados se era possível fazer a reciclagem de resíduos domésticos, 71\% (177/250) responderam corretamente e o restante mostrou desconhecer as opções de reciclagem para tais materiais.

A questão seguinte mostrou-se interessante, pois as respostas convergiram para um mesmo destino. A pergunta foi "De que maneira você descarta os seus resíduos domésticos?". Como resposta, a grande maioria citou os ecopontos.

O quadro 1 demonstra que a questão dos resíduos sólidos urbanos em Portugal era insustentável até 1995, porém, a partir do ano de 1996, a gestão de resíduos sólidos urbanos foi sendo alterada progressivamente, tendo sido iniciada com a aprovação do PERSU - Plano Estratégico Setorial dos Resíduos Sólidos Urbanos. Neste plano foram definidas algumas prioridades para alavancar a sustentabilidade do País, entre elas aparece o encerramento e a recuperação ambiental dos lixões, a criação e construção de infraestrutura de coleta, transporte, tratamento e destino final dos RSU's e similares e a criação da base de apoio ao desenvolvimento da coleta seletiva e da reciclagem (POLZIN, 2004).

A compostagem é vista como um hábito que pode ser desenvolvido em casa para dar o destino

Quadro 1. Tratamentos e destinos finais dos resíduos sólidos urbanos de Portugal em 1995.

\begin{tabular}{|c|c|c|}
\hline Tratamentos e destinos finais & Quantidade (milhões de t/ano) & Porcentagem (\%) \\
\hline Lixão & 1,924 & 60 \\
\hline Lixão controlado & 0,513 & 16 \\
\hline Aterro controlado & 0,471 & 15 \\
\hline Compostagem & 0,299 & 9 \\
\hline Total & 3,207 & 100 \\
\hline
\end{tabular}

Fonte: IR, 1999. 


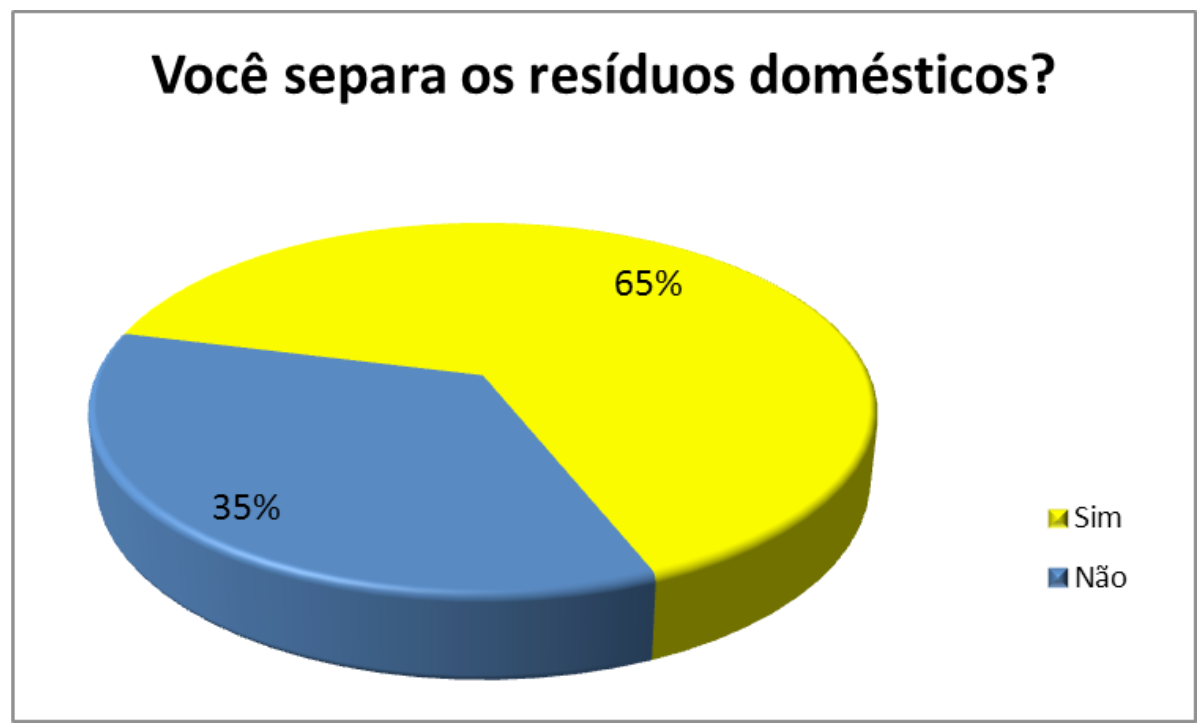

Figura 8. Hábito de separação de lixo doméstico por parte dos entrevistados.

\section{Você costuma fazer compostagem?}

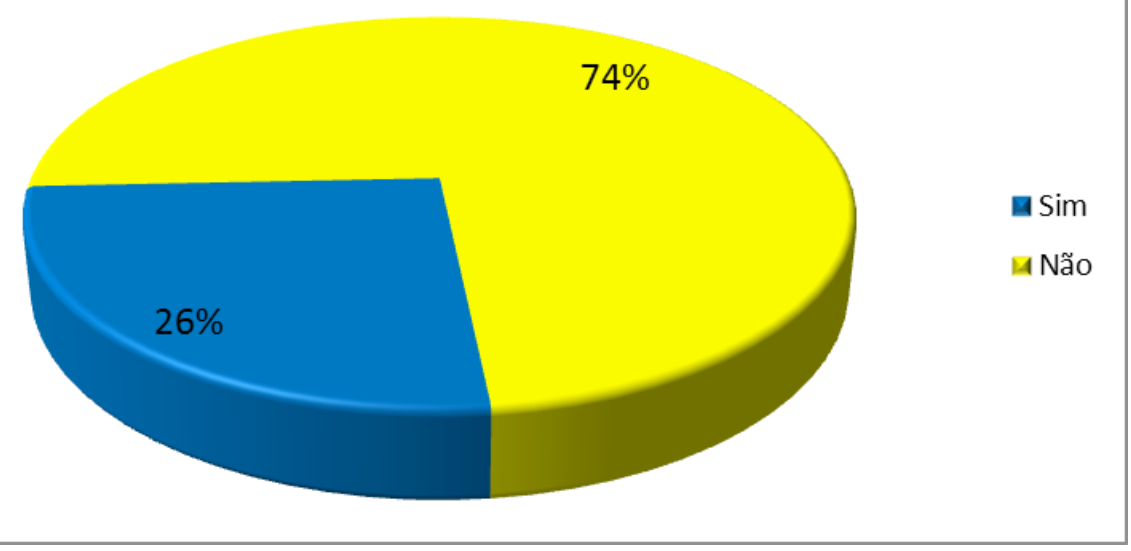

Figura 9. Compostagem do lixo doméstico.

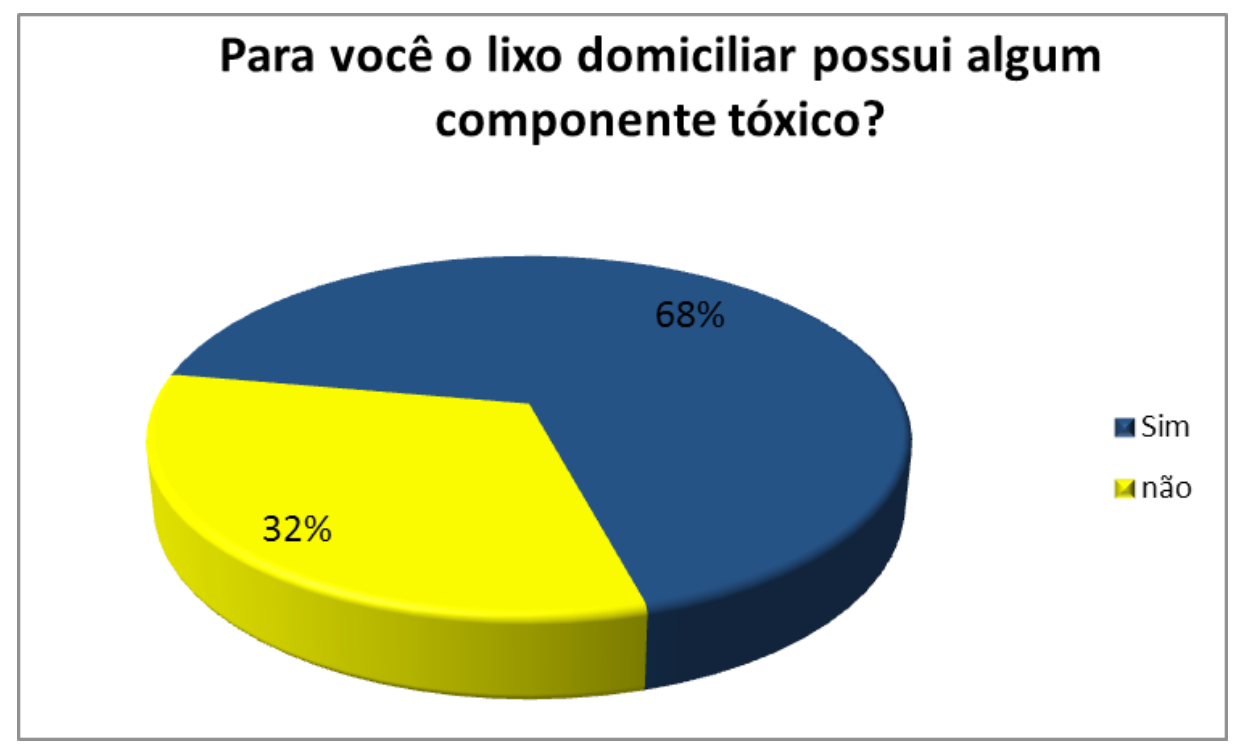

Figura 10. Conhecimento à respeito da toxidadade do lixo domicilar. 
correto aos resíduos orgânicos, desde que se tenha um espaço adequado para isso. Quando não há essa possibilidade, existe outra forma de contribuir para o meio ambiente e consequentemente para a melhora da qualidade de vida que é fazendo a separação do lixo, sendo que esta pode ser simples ou completa, porém, de qualquer forma a separação do lixo seco e orgânico já ajuda bastante para que os catadores destinem corretamente o lixo que eles recolhem (GALVÃO, 2007).

Por isso a quarta (Figura 8) e sexta (Figura 9) perguntas respectivamente objetivavam saber se o entrevistado realizava a separação dos resíduos domésticos ou costumava fazer compostagem dos seus resíduos domiciliares, caso a resposta fosse positiva deveria-se explicar de que maneira isso era feito e se desta forma ele(a) estava contribuindo para a preservação do meio ambiente.

A oitava questão tratava-se dos problemas que o lixo domiciliar possa trazer para a saúde humana por meio de algum componente tóxico e as respostas obtidas foram às representadas pela figura 10 .

No universo de pessoas amostradas, 58\% $(145 / 250)$ das pessoas mostraram desconhecer se a região do Algarve possui algum sistema de coleta de resíduos domésticos e aproximadamente $73 \%(182 / 250)$ mostraram-se insatisfeitos com a separação de lixo realizada pelos residentes da área local e afirmaram que existem poucas informações referentes ao que pode e o que não pode ser reciclado. Segue abaixo as figuras 11 e 12 que correspondem respectivamente às afirmações feitas acima.

Mais do que respostas objetivas, coletou-se também a opinião dos entrevistados que mostraram-se preocupados com o rumo que a sociedade está tomando em relação às questões ambientais. A maioria das pessoas que procuraram deixar sua opinião por escrito alertou para o descaso de autoridades e a falta de cultura do povo.

No decorrer do questionário abordou-se o tema da coleta seletiva, em uma questão simples sobre o conceito do termo. Pode-se analisar as respostas de duas formas, uma dessas formas é que $84 \%(210 / 250)$ sabem o significado do termo "coleta seletiva", o que considera-se uma porcentagem alta, porém, se quisermos realmente que haja um desenvolvimento sustentável, devemos preencher esse número e chegar aos $100 \%$ de pessoas informadas sobre temas básicos de sustentabilidade. Pode-se conferir as respostas na figura 13.

A seguinte questão diz respeito aos aterros sanitários (figura 14). Nesta questão deve-se fazer um parêntese para o total desconhecimento do universo estudado sobre a finalidade de um aterro sanitário, pois a maioria das respostas, cerca de $67 \%(167 / 250)$ mostrou desconhecer que aterros sanitários são ambientes controlados e impermeáveis para reter os contaminantes.

Procurou-se abordar amplamente os resíduos sólidos, de modo que abrangesse também os resíduos perigosos produzidos nas residências, desta forma questionou-se se as lâmpadas fluorescentes, pilhas e medicamentos vencidos poderiam ser descartados como lixo doméstico em aterro sanitário.

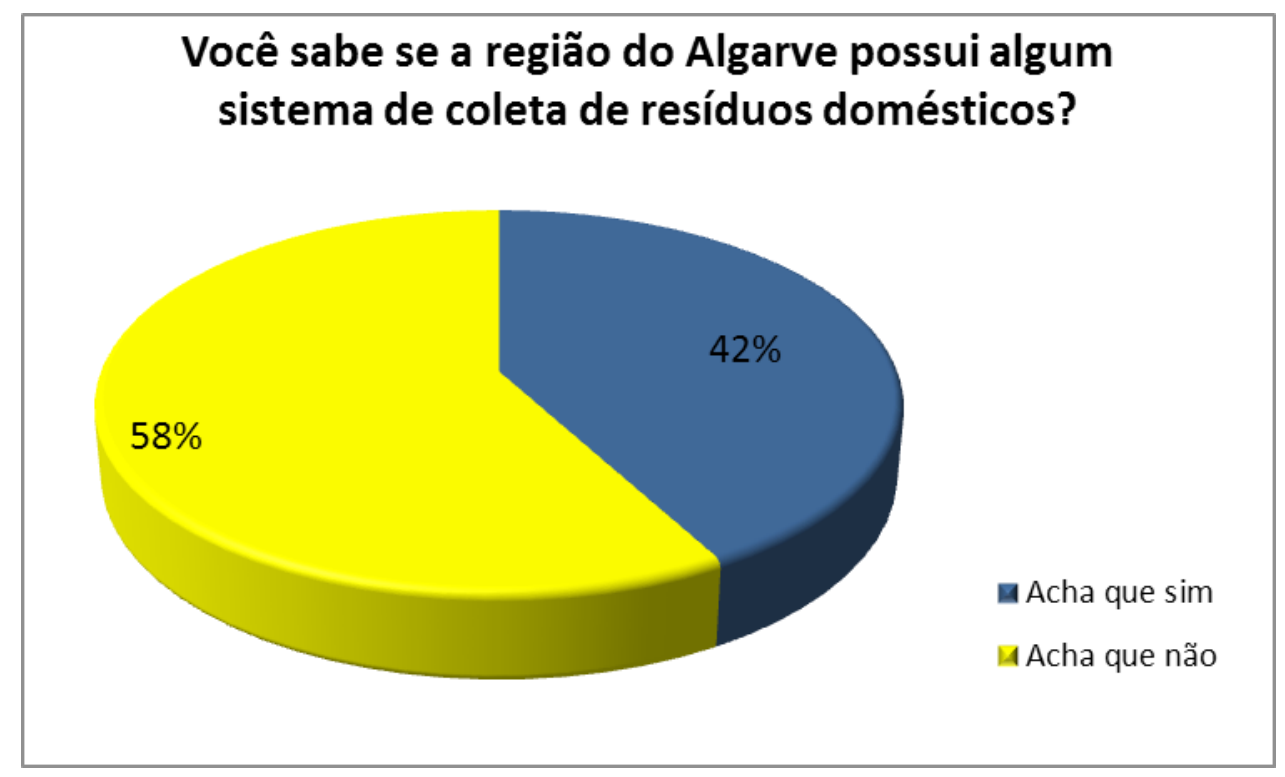

Figura 11. Sistema de coleta na região do Algarve 


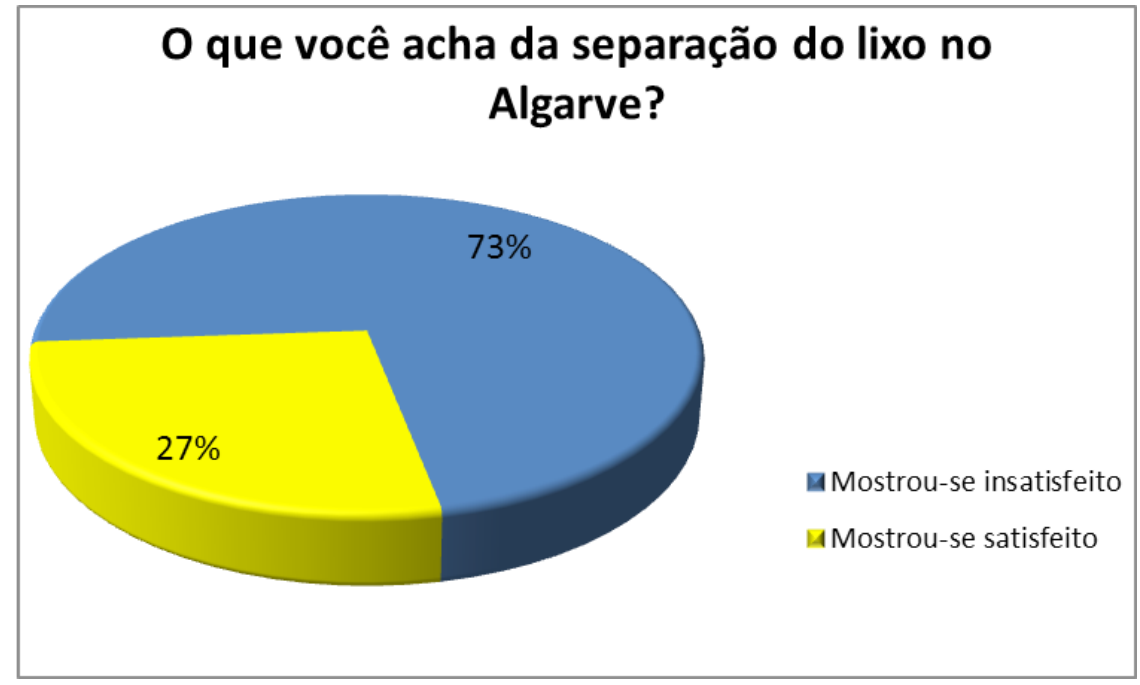

Figura 12. Opinião acerca da separação de lixo realizada no Algarve

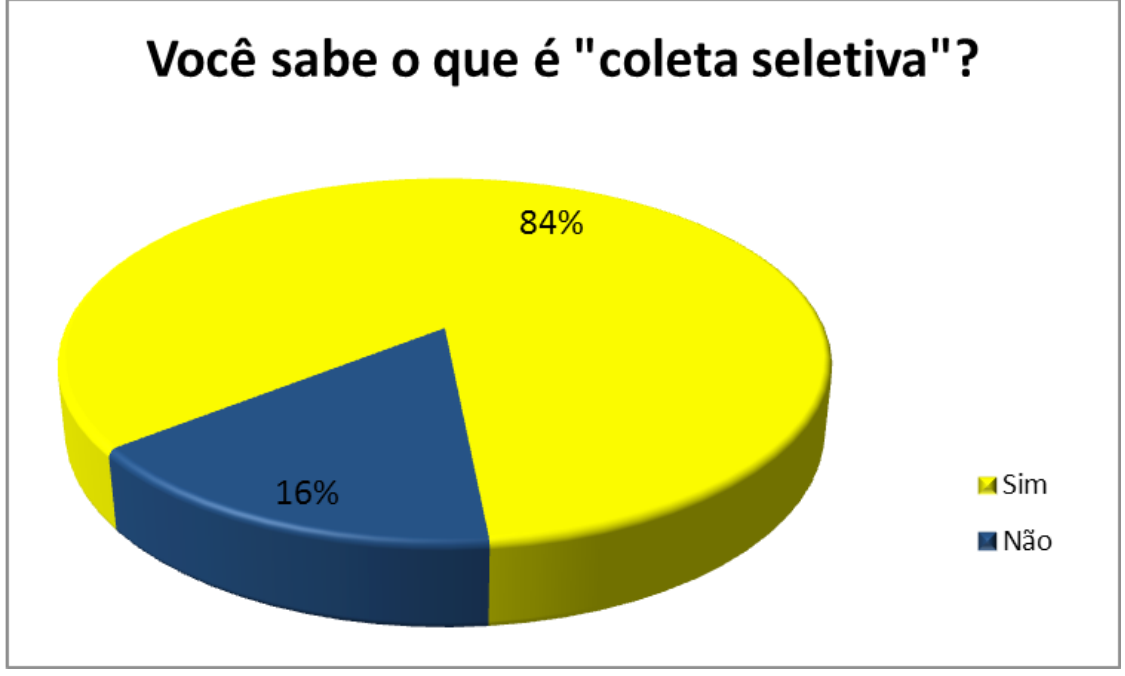

Figura 13. Conceito do termo "coleta seletiva"

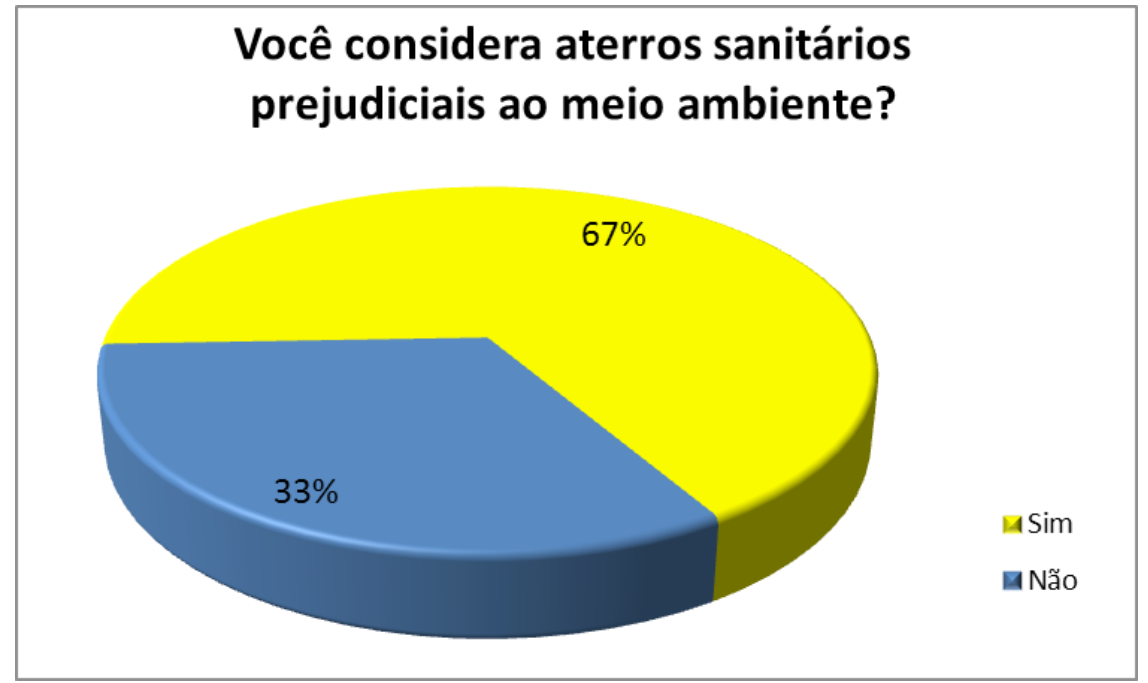

Figura 14. Conhecimento do público à respeito dos aterros sanitários 


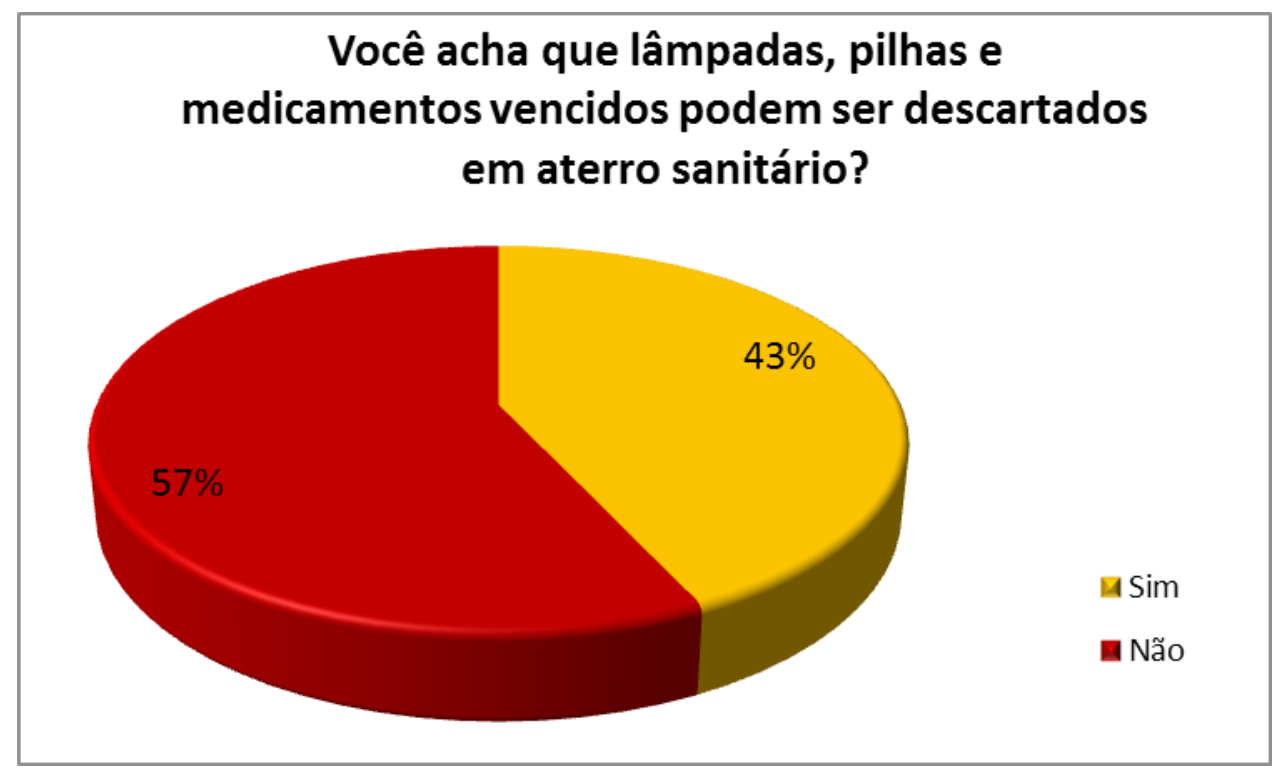

Figura 15. Lâmpadas, pilhas e medicamentos vencidos

Nesta questão houve equilibrio e indecisão pois a maioria das justificativas foram equivocadas, desta forma cerca de $57 \%(142 / 250)$ das pessoas responderam que estes tipos de resíduos não devem ser descartados em aterros sanitários pois produzem subprodutos tóxicos, porém não sabem ou não opinaram o tratamento que tal resíduo sofre.

\section{CONCLUSÃO}

Com base no que é absorvido, seja por conhecimento empírico ou pelo que a mídia tem destacado nos últimos anos, tem-se o conhecimento de que nossas ações vem sofrendo suas consequências (por mais pequenas que estas sejam). Percebe-se desta forma que o grande público de 250 pessoas entrevistadas adere às questões sustentáveis, porém, ainda não há toda comoção necessária em prol do meio ambiente para que consigamos completar um ciclo de uso e reúso até o descarte final. Alguns hábitos essenciais como a separação do lixo, compostagem, reaproveitamento e busca por maiores informações carecem de fomento por meio das autoridades responsáveis pelo setor do meio ambiente.

Questões ligadas a clima, alimentos, saúde, recursos hídricos e resíduos sólidos fazem parte da agenda da sociedade. Garantir isso para uma população crescente de perfil fundalmentalmente urbano e mais exigente quanto à qualidade dos serviços, do produto e do ambiente é um enorme desafio aos tomadores de decisão, particularmente em cenários de mudança climática com intensa degradação do solo e da água, necessitando desta forma mais estudos e incentivos para a prática de atividades sustentáveis.

\section{REFERÊNCIAS}

BRASIL. NBR 10004, 30 de Novembro de 2004. Disponível em: http://www.aslaa.com.br/legislacoes/NBR\%20n\%2010004-2004.pdf. Acesso em: 10 mai. de 2013.

DIAS, G. F. Educação Ambiental: princípios e práticas. 1. ed. GAYA, 1992. 399 p.

CARVALHO, I. C. M. Ambientalismo e juventude: o sujeito ecológico e o horizonte da ação política contemporânea In: Novaes, Regina e Vannuchi, Paulo (orgs). Juventude e Sociedade; trabalho, educação, cultura e participação. Fundação Perseu Abramo e Instituto da Cidadania, São Paulo, 2004.

FERNANDES, P. A. L. Estudo Comparativo e Avaliação de Diferentes Sistemas de Compostagem de Resíduos Sólidos Urbanos, 1999. Disponível em: https:// iconline.ipleiria.pt/bitstream/10400.8/52/1/MSc_Thesis_PauloFernandes.pdf. acesso em: 6 dez. de 2012 .

GALVÃO, C. Práticas de Pesquisa em Educação Ambiental em Diferentes Espaços Institucionais. Educação Ambiental em Portugal: Investigação Sobre as Práticas. Universidade de Lisboa. Pesquisa em Educação Ambiental, Vol. 2, n. 1 - pp. 95-110, 2007. 
INE, Instituto Nacional de Estatística, 2011.

Disponível em: < http://www.ine.pt/xportal/

$\mathrm{xmain}$ ?xpid=INE\&xpgid=ine_indicadores\&indOcorrCo

$\mathrm{d}=0005889 \&$ selTab=tab0>. Acesso em: 01 out. de 2013.

ISEL, Instituto Superior de Engenharia de Lisboa, 2001. Que soluções para o tratamento dos Resíduos Sólidos Industriais?. Disponível em: < http://www.deetc.isel. ipl.pt/jetc05/CCTE02/papers/finais/quimica/52.PDF>. Acesso em: 01 out. de 2013.

OLIVEIRA, R.L. Logística Reversa: a utilização de um sistema de informações Geográficas da Coleta Seletiva de Materiais Recicláveis, 2011. Disponível em: <http:// juno.unifei.edu.br/bim/0038208.pdf $>$. Acesso em: 01 out. de 2013.

POLZIN, D. A. O. F. M. Gestão dos resíduos sólidos urbanos: análise comparativa entre Portugal e o Brasil. 2004. 0 f. Dissertação (Mestrado em Ciência Ambiental) - Universidade Federal Fluminense

TROTTA, P. A Gestão de Resíduos sólidos Urbanos em Portugal, 2011. Disponível em: http://www. excelenciaemgestao.org/Portals/2/documents/ cneg7/anais/T11_0350_2173.pdf. Acesso em: 7 dez. de 2012. 